Научная статья

УДК $101.1:: 316$

DOI: $10.18101 / 1994-0866-2020-4-24-30$

\title{
АКСИОЛОГИЧЕСКИЙ АНАЛИЗ ЦИФРОВИЗАЦИИ РОССИЙСКОГО ОБРАЗОВАНИЯ
}

\author{
(C) Седов Дмитрий Николаевич \\ аспирант, \\ Нижегородский институт управления — филиал \\ Российской академии народного хозяйства и государственной службы \\ при президенте Российской Федерации \\ Россия, 603950, г. Нижний Новгород, пр-т Гагарина, 46 \\ sedoffmail@yandex.ru
}

Аннотация. В данной статье осуществлен аксиологический анализ влияния процессов цифровизации на образовательную культуру. Выделяются ценности образовательной культуры и цифрового сообщества, проанализированы перспективные стороны и потенциальные проблемы цифровизации образования. Автор статьи в результате аксиологического анализа приходит к выводу, что российскому образованию необходимо адаптироваться к новым условиям, внимательно отслеживать тренды и применять лишь те виды технологий, которые окажутся эффективными. Появляются новые вызовы для системы образования, которые заключаются в особенностях использования инновационных технологий. Сделан вывод о том, что процесс цифровизации образования не противоречит ценностям образовательной культуры России, но к техническим нововведениям следует относиться внимательно, детально изучая цифровые продукты с разных точек зрения - аксиологической, педагогической, научной и социальной.

Ключевые слова: образование; цифровизация; цифровизация образования; образовательная культура; диджитализация культуры; цифровое сообщество; цифровое образование.

\section{Для цитирования}

Седов Д. Н. Аксиологический анализ цифровизации российского образования // Вестник Бурятского государственного университета. Философия. 2020. Вып. 4. C. 24-30.

В настоящее время изучение процесса цифровизации является одной из важных задач для исследователей разных направлений. Цифровизация (или диджитализация) - это процесс внедрения инновационных цифровых технологий в различные сферы общества, а также перевод различных процессов в цифровой формат.

В современной России активно происходит процесс оцифровывания образования, например, правительством была разработана программа "Цифровая образовательная среда" ${ }^{1}$. Главные задачи программы - объединение онлайн-курсов

${ }^{1}$ URL: http://neorusedu.ru (дата обращения: 03.11.2020). 
на одной платформе для упрощения доступа, разработка и внедрение системы оценки качества онлайн-курсов, открытие региональных центров компетенций в области онлайн-обучения для интеграции специалистов в процесс создания онлайн-курсов, а также разработка систем повышения квалификации работников образования в области цифровой педагогики.

Современное оцифрованное обучение чаще является результатом деятельности отдельных фирм, групп и ассоциаций, которые начали активно сотрудничать с российскими университетами лишь в последние годы. Основные виды их взаимодействия - организация курсов, онлайн-лекториев, внедрение и применение инновационных цифровых технологий в образовательном процессе.

Изменения в сфере образования, связанные с цифровизацией, требуют глубокого и детального исследования, ведь меняется не только процесс с технической точки зрения, изменения претерпевает вся образовательная культура России. Новые условия требуют появления новых компетенций и навыков как от преподавателей, так и от студентов, в цепочке образовательного процесса «преподаватель - студент» появляется новое звено - техника [4].

Один из главных вопросов, ставших актуальными в связи с изменениями в сфере образования, - как именно изменится образовательная культура с применением инновационных технологий. Повысится ли качество образования, или нас ждет много вызовов, справиться с которыми будет трудно? [1]

Различные аспекты обозначенной проблемы были исследованы С. Л. Ивашевским [2], который изучил динамику изменений образовательной культуры в российских университетах, Г. А. Мавлютовой, выделившей основные направления цифровых изменений в образовании [6], Н. П. Петровой, Г. А. Бондаревой [9], которые исследовали внедрение цифровых технологий в образовательный процесс, Н. Ю. Игнатовой, изучившей особенности образования в цифровую эпоху [5], Е. В. Николаевой, которая выделила основные константы и паттерны цифровой культуры [8], М. А. Маниковской, обозначившей новые вызовы морали [7].

Цель данной работы - провести сравнительный анализ ценностей образовательной культуры России и тенденций развития цифрового сообщества, выделить основные направления, по которым произойдет качественное улучшение образовательного процесса и обозначить главные проблемы цифровой модернизации образовательной сферы. Для достижения цели необходимо решить следующие задачи: выявить традиционные ценности образовательной среды в России и ценности цифрового сообщества, обнаружить основные противоречия, выделить перспективные направления и проблемы их взаимодействия. При этом под образовательной культурой России мы предлагаем понимать ту сферу общей национальной культуры, в которой отражены идеалы и ценности образовательного процесса, а под цифровым сообществом - инициаторов и пользователей достижений современной цифровой технокультуры.

В качестве основополагающего метода в данной работе был выбран метод сравнительного анализа, на основании которого у автора появилась возможность выделить главные схожие черты и различия в ценностях традиционной российской образовательной культуры и ценностях современного цифрового сообщества. 
В качестве основы для определения традиционных ценностей российского образования был проведен анализ федерального закона «Об образовании в Российской Федерации» ${ }^{1}$. Выявление основных ценностей цифрового сообщества более сложная задача по причине того, что процессы диджитализации не представляют собой единую систему, опирающуюся на общий фундамент ценностных ориентиров. В связи с этим для выявления аксиологической основы данных процессов были взяты принципы платформы открытого образования, которая была создана Ассоциацией "Национальная платформа открытого образования" ${ }^{2}$ в сотрудничестве с вузами России. Платформа является одной из крупнейших на территории Российской Федерации, в настоящее время объединяет более 670 курсов от университетов России, количество направлений на данный момент более 200, среди которых есть технические, гуманитарные, медицинские и творческие, авторы активно работают над курсами по новым направлениям. Деятельность платформы была стандартизирована рабочей группой Совета Минобрнауки России.

Одной из главных ценностей российского образования, исходя из закона об образовании, является ценность равного доступа к образованию. Рассматривая закон, мы видим, что формулировка «равный доступ к образованию» означает такой способ организации образовательного процесса, что образование не зависит «от пола, расы, национальности, языка, происхождения, имущественного, социального и должностного положения, места жительства, отношения к религии, убеждений, принадлежности к общественным объединениям, а также других обстоятельств» ${ }^{3}$.

Следовательно, принцип равенства является важным элементом в организации образовательного процесса, что позволяет стране подготавливать кадры для всех секторов экономики, предоставляя жителям возможность получить качественное образование в любой точке России. Также для равного доступа людей к любому образовательному профилю в российских вузах есть места, финансируемые из государственного бюджета. Главная проблема - для получения образования по некоторым профилям жителям даже крупных городов приходится поступать в иногородние университеты, что ставит под сомнение полноценное соблюдение данного принципа.

Ценность свободы в образовании также является одной из важнейших в нашей стране. Как утверждает закон: «под свободой преподавания подразумевается свободное выражение преподавателем своего мнения; свобода от вмешательства в профессиональную деятельность, а также некоторые другие права и свободы» ${ }^{4}$.

${ }^{1}$ Об образовании в Российской Федерации: федер. закон от 29 декабря 2012 г. № 273-Ф3, с изменениями 2020 г.

${ }^{2}$ URL: https://openedu.ru (дата обращения: 03.11.2020).

${ }^{3}$ Об образовании в Российской Федерации: федер. закон от 29 декабря 2012 г. № 273-Ф3, с изменениями 2020 г.

${ }^{4}$ Об образовании в Российской Федерации: федер. закон от 29 декабря 2012 г. № 273-Ф3, с изменениями 2020 г. 
Анализируя данный пункт закона, мы можем сделать вывод о том, что ценность свободы выражена в том, что нет сторонних факторов, которые бы препятствовали свободе слова, кроме тех, которые оговорены другими законами - запрещена политическая пропаганда, принуждение к принятию или отказу от религиозных убеждений и прочие нормы.

Также важными ценностями в образовательной культуре являются недопустимость дискриминации, гуманистический характер образовательного процесса, воспитание в гражданах трудолюбия, взаимоуважения, патриотизма и ответственности. Одной из важных процессуальных установок является единство образовательного процесса на территории страны, а также адаптивность образования. Среди главных ценностей цифрового сообщества можно выделить:

1) принцип доступности и открытости. У многих ресурсов есть возможность мультиплатформенного использования, что значительно расширяет возможности студентов и снижает требования к технической оснащенности, тем самым способствуя снижению порога вхождения в цифровой образовательный процесс;

2) соблюдение ценностей авторского права. Все материалы, которые используются в цифровых образовательных продуктах, обязательно должны быть использованы в соответствии с нормами права и соответствовать законодательству;

3) доступность для лиц с ограниченными возможностями, что позволяет сделать образовательный процесс открытым для всех граждан страны. Также для многих платформ в системе требований предусмотрено обязательное наличие команды поддержки, это позволяет решить возникающие проблемы при обучении лиц с ограниченными возможностями;

4) принцип фокусировки на образовательном процессе, который заключается в том, что пользователь платформы не видит внешних раздражающих элементов, таких как баннеры, реклама и прочий отвлекающий контент.

Выделив основные ценностные ориентировки двух образовательных сфер, мы можем провести аналитическое сравнение. Результаты сравнительного анализа представлены в таблице 1.

Таблииа 1

Результаты сравнительного анализа

\begin{tabular}{|l|l|l|}
\hline Ценностный аспект & $\begin{array}{l}\text { Российская сфера образо- } \\
\text { вания }\end{array}$ & Цифровое сообщество \\
\hline Принцип равенства & $\begin{array}{l}\text { Присутствует, закреплен в } \\
\text { законе и соблюдается об- } \\
\text { разовательными организа- } \\
\text { циями }\end{array}$ & $\begin{array}{l}\text { Присутствует, выражен в техни- } \\
\text { ческой доступности образова- } \\
\text { тельных материалов }\end{array}$ \\
\hline Принцип свободы & $\begin{array}{l}\text { Присутствует, с учетом } \\
\text { ограничений, предусмот- } \\
\text { ренных в других законах }\end{array}$ & $\begin{array}{l}\text { Присутствует в полной мере, так } \\
\text { карганизовать свой образова- } \\
\text { тельый курс может практиче- } \\
\text { ски любой, но возникает вопрос } \\
\text { качества материала и целесооб- } \\
\text { разности изложения той или } \\
\text { иной его части }\end{array}$ \\
\hline
\end{tabular}




\begin{tabular}{|l|l|l|}
\hline $\begin{array}{l}\text { Недопустимость дис- } \\
\text { криминации }\end{array}$ & Принцип соблюдается & $\begin{array}{l}\text { Не имеет привязки к цифровой } \\
\text { форме образовательного процес- } \\
\text { са }\end{array}$ \\
\hline $\begin{array}{l}\text { Воспитание в гражда- } \\
\text { нах ответственности, } \\
\begin{array}{l}\text { патриотизма, взаимо- } \\
\text { уважения }\end{array}\end{array}$ & $\begin{array}{l}\text { Принцип соблюдается, но } \\
\text { ности вуза в целом }\end{array}$ & $\begin{array}{l}\text { Принцип не является обязатель- } \\
\text { ным для соблюдения, так как } \\
\text { онлайн-платформы, сотрудни- } \\
\text { чающие с вузами, не проводят } \\
\text { комплексной работы, ограничи- } \\
\text { ваясь проведением курсов по } \\
\text { отдельным направлениям }\end{array}$ \\
\hline
\end{tabular}

Выделим основные перспективные направления сотрудничества университетов и образовательных платформ, которые могут быть реализованы в рамках диджитализации обучения:

1) создание совместных образовательных продуктов. В данном процессе платформа играет лишь техническую роль, основная образовательная составляющая зависит от образовательного учреждения, а значит, предполагает соблюдение всех норм и следование ценностям российской образовательной культуры. В качестве примера такого продукта могут быть приведены курсы Национальной платформы открытого образования, которые организованы несколькими российскими вузами. Такие курсы помимо наглядного обучающего материала со вспомогательными элементами содержат также и тесты для проверки знаний студентов, что потенциально является подтверждающим фактором эффективности;

2) открытие онлайн-лекториев с участием преподавателей российских и зарубежных университетов. Такие лектории позволят студентам и всем желающим получать знание по предметам, которые являются для них элементом непрофессиональной сферы интересов. Такие лектории призваны повысить общий уровень образовательной культуры, предоставляя людям возможность бесплатно ознакомиться с последними достижениями науки и культурными произведениями;

3) создание инновационных технических продуктов, которые могут быть применены студентами технических специальностей. Программное обеспечение не только упростит образовательный процесс, но и положительно повлияет на практический аспект обучения - большинство профессий сейчас оцифровываются в той или иной степени, и у студентов появится возможность практического применения знаний в дальнейшей деятельности. При должном подходе данное нововведение может повлиять на «образовательный нигилизм», частично связанный с отрывом сферы образования от практической ориентированности [3].

Помимо новых возможностей применение цифровых продуктов также приносит и новые вызовы, с которыми нужно справиться:

1) до сих пор открыто стоит вопрос о качестве обучения, неразрешенными остаются проблемы проверки знаний, полноты сформированных курсов, их теоретической и практической значимости;

2) как именно сертификаты о прохождении того или иного курса могут быть использованы студентом? Будут ли они засчитываться в виде льгот при поступлении или в качестве замены очным занятиям? Сможет ли цифровой сертификат 
заменить оценку в зачетке? Данный процесс требует серьезного планирования на государственном уровне;

3) как изменится культура получения новых знаний? Не станет ли отсутствие прямой связи «преподаватель - студент» ключевым фактором трансформации образовательной культуры в худшую сторону?

4) технические требования к слушателям курса постоянно снижаются, материалы оптимизируются и становятся доступны все большему количеству пользователей, но вопрос об общей доступности все равно остается открытым. Принцип равенства теряет свою ценность, так как слушатели курса с большими техническими возможностями смогут получить цифровой продукт более высокого уровня, в отличие от тех, кому техническая составляющая не позволяет в полной мере пользоваться платформами.

Заключение. Исходя из выделенных нами перспектив и проблем, а также из результатов сравнительного анализа, мы видим, что процессы совершенствования образования требуют адаптации к новым условиям диджитализации. Безусловно, процессы цифровизации влияют на образовательную культуру, нам следует быть крайне осторожными при внедрении новых цифровых продуктов в образовательный процесс. Несмотря на практически полное совпадение ценностных приоритетов, их последовательное соблюдение при использовании цифровых продуктов остается под вопросом. Следование традиционным ценностям российской образовательной среды не может быть заложено только в материал учебного курса, оно зависит и от внешних факторов. Так, фактор технической оснащенности при недостаточном к нему внимании может повлиять на реализацию ценностей открытости и равенства доступа в образовании, а некоторые аспекты традиционного обучения и вовсе не могут быть перенесены в цифровое пространство, например прямой диалог студента и преподавателя, если курс лекций предзаписан. Также среди факторов, осложняющих эффективное внедрение онлайн-образование, - слабые возможности контроля образовательного процесса, студенты могут не смотреть лекции и найти ответы на контрольные вопросы в интернете, а на очных лекциях их внимание контролируется преподавателем. Эти моменты должны быть обязательно учтены при проектировании и реализации цифровых продуктов в российском образовательном пространстве.

\section{Литература}

1. Кузнецова Т. Ф. Цифровизация и цифровая культура // Горизонты гуманитарного знания. 2019. № 2. URL: https://cyberleninka.ru/article/n/tsifrovizatsiya-i-tsifrovaya-kultura (дата обращения: 03.11.2020).

2. Ивашевский С. Л. Идеал образованности как фактор развития правовых норм образования // Вестник Нижегородского университета им. Н. И. Лобачевского. Сер.: Социальные науки. 2007. № 3(8). С. 193-197.

3. Ивашевский С. Л. Образовательная культура в аспекте ценностно-нормативного подхода // Вопросы культурологии. 2007. № 9. С. 28-30.

4. Ивашевский С. Л. Идеал образованного человека: традиции и современность: автореф. дис. ... филос. наук. Н. Новгород: НГПУ, 1999. 26 с.

5. Игнатова Н. Ю. Образование в цифровую эпоху. Нижний Тагил, 2017. 118 с. 
6. Мавлютова Г. А. Цифровизация в современном высшем учебном заведении // ИБР. 2018. № 3(32). URL: https://cyberleninka.ru/article/n/tsifrovizatsiya-v-sovremennomvysshem-uchebnom-zavedenii (дата обращения: 18.10.2020).

7. Маниковская М. А. Цифровизация образования: вызовы традиционным нормам и принципам морали // Власть и управление на Востоке России. 2019. № 2(87). URL: https://cyberleninka.ru/article/n/tsifrovizatsiya-obrazovaniya-vyzovy-traditsionnym-normam-iprintsipam-morali (дата обращения: 20.10.2020).

8. Николаева Е. В. Парадигматические константы и структурно-семантические паттерны цифровой культуры // Обсерватория культуры. 2014. № 3. С. 26-33.

9. Петрова Н. П., Бондарева Г. А. Цифровизация и цифровые технологии в образовании // MНКО. 2019. № 5(78). URL: https://cyberleninka.ru/article/n/tsifrovizatsiya-itsifrovye-tehnologii-v-obrazovanii (дата обращения: 18.10.2020).

10. Стрекалова Н. Б. Риски внедрения цифровых технологий в образование // Вестник Самарского университета. История, педагогика, филология. 2019. № 2. URL: https://cyberleninka.ru/article/n/riski-vnedreniya-tsifrovyh-tehnologiy-v-obrazovanie (дата обращения: 03.11.2020).

Статья поступила в редакцию 10.11.2020; одобрена после рещензирования 16.11.2020; принята к публикаџии 25.11.2020.

\title{
AXIOLOGICAL ANALYSIS OF THE DIGITALIZATION OF RUSSIAN EDUCATION
}

\author{
Dmitry N. Sedov
}

Research Assistant,

Nizhny Novgorod Institute of Management - Branch of Russian Presidential Academy of National Economy and Public Administration

46 Gagarina Prospect, Nizhny Novgorod 603950, Russia

sedoffmail@yandex.ru

Abstract. The article presents an axiological analysis of the impact of digitalization processes on educational culture. We have emphasized the values of educational culture and the digital community, prospects and potential problems of education digitalization. As a result of an axiological analysis, we come to the conclusion that Russian education needs to adapt to new conditions, to monitor closely trends and apply only effective technologies. New challenges for the education system lie in the application of innovative technologies. The analysis shown that the process of education digitalization does not contradict the values of Russian educational culture, but before the implementation of technical innovations, all digital products should be studied in detail from a variety of perspectives, including in particular axiological, pedagogical, scientific and social ones.

Keywords: education; digitalization; digitalization of education; educational culture; digitalization of culture; digital community; digital education. 